\title{
BSPD publishes MIH paper
}

A briefing paper on molar incisor hypomineralisation (MIH) has been published by the British Society of Paediatric Dentistry (BSPD). ${ }^{1}$ The aim of the paper is to build awareness of the condition and also to support the dental profession in the diagnosis and management of MIH.

Compiled on behalf of BSPD by Stephen Fayle, a Consultant at Leeds Dental Institute, Chairman of the Yorkshire Managed Clinical Network and Chair of the Commissioning Standard for Paediatric Dentistry working group, the position statement helps advise on the appropriate management of MIH so the long-term impact can be minimised.

The statement incorporates new advice published in the $B D J$ which states that because MIH is a common condition, it should be treated in primary care wherever possible. $^{2}$

Mr Fayle said: 'We endorse this advice for less severe and less complex cases whilst also recommending that young patients more severely affected by MIH should be referred to a specialist for a treatment plan and advice by the age of nine.

'The paediatric dentist can then advise if the affected teeth should be restored and maintained or whether extraction is indicated and if so, when the optimum time for extraction would be. This also provides the opportunity for discussion about the most appropriate management of any cosmetic concerns arising from affected anterior teeth.'

In some more complex cases, an opinion from an orthodontist may also be needed, especially for children with significant developing malocclusion. Specialist collaboration enables the timing and pattern of any extractions to be planned to optimise the eventual orthodontic outcome.

In order that all children have access to a paediatric specialist when they need one,
BSPD continues to call for more paediatric specialists to be trained and equally distributed throughout the UK.

Mr Fayle said: 'It is vital that the whole dental team, including dental therapists, dental hygienists and dental nurses, are familiar with MIH and with the most appropriate preventive and treatment strategies, to help ensure favourable results. Dental caries frequently complicates the presentation of MIH so proactive prevention can decrease morbidity whilst improving outcomes.'

\section{References}

1. British Society of Paediatric Dentistry. Molar Incisor Hypomineralisation (MIH). A BSPD position paper on the dental condition affecting $1 \mathrm{~m}$ UK children. January 2020. Available at: https://www.bspd.co.uk/Portals/0/ MIH\%20statement\%20final\%20Jan\%202020.pdf (accessed 28 January 2020).

2. Almuallem Z, Busuttil-Naudi A. Molar incisor hypomineralisation (MIH) - an overview. Br Dent J 2018; 225: 601-609.

\section{BOOK REVIEW}

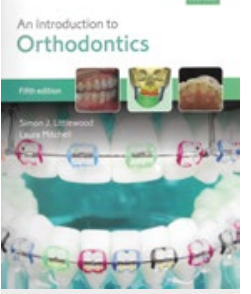

\section{AN INTRODUCTION TO ORTHODONTICS, FIFTH EDITION}

Simon J. Littlewood, Laura Mitchell;

2019; Oxford University Press; £46.99; pp 368;

ISBN: 9780198808664

An introduction to orthodontics encapsulates the fundamental topics and concepts within this specialty by managing to concisely cover the foundations of contemporary orthodontic care in its impressively structured 25 chapters. As a result of this, it appeals to all: from undergraduate and postgraduate students, to general dental practitioners, or simply any individual who wishes to delve into the exciting world of orthodontics.

The early chapters explore the rationale for orthodontic treatment, classifying, assessing and treating malocclusions. They also provide appropriate information to consider in history-taking, assessing and examining patients, as well as appropriate special investigations. Later chapters explore these areas in greater detail, as well as discussing surgical considerations, craniofacial anomalies, orthodontic first aid and cleft. Even in its fifth edition, this book still remains topical, current and relevant: this is evident through new and exciting chapters which include an updated discussion of hypodontia and orthodontics, as well as the increasingly popular topic of clear aligners and orthodontics. Each malocclusion has its own dedicated chapter to ensure that readers are provided with a thorough and evidence-based insight of the aetiology and management. Readers are provided with ample information to inform them of appropriate treatment modalities within orthodontics, as well as treatment aims, throughout each chapter. These are supplemented with evidencebased discussions and references to ensure readers are directed to appropriate sources for further reading. An electronic hyperlink to references is included at the end of each chapter to facilitate wider reading and increase accessibility, which is a highly useful implementation. All chapters include useful case-based discussions and an array of colourful illustrations, diagrams and clinical photographs to enhance discussion. Specific learning objectives and key point summaries throughout enable readers to delve into areas as little or as much as they desire, encouraging both in-depth and targeted learning.

Now in its fifth edition, An introduction to orthodontics already has a well-secured place on the bookshelves of dental students. With a proven popular history, the relevance and usefulness of the content within this book is indubitable. It covers the essential information to provide a thorough knowledge of key concepts within orthodontics whilst eloquently exploring other topical and interesting areas. It provides an excellent and thorough discussion of contemporary orthodontic practice whilst supplying a detailed insight into the theoretical principles that form the basis of clinical considerations and treatments. As a result of this, I have no hesitation in recommending it to all readers.

Amardeep Singh Dhadwal, Dental Core Trainee in Birmingham Dental Hospital and School of Dentistry, Birmingham Community Healthcare Trust 